\title{
THE SUMMER MEETING IN HANOVER
}

The forty-sixth Summer Meeting of the Society and the twentysecond Colloquium were held at Dartmouth College, Hanover, New Hampshire, from Tuesday to Thursday, September 10-12, 1940. The Mathematical Association of America met on Monday morning and afternoon and the Institute of Mathematical Statistics on Tuesday morning and afternoon and Wednesday and Thursday mornings. About four hundred fifty persons attended the meetings, among whom were the following two hundred ninety-eight members of the Society:

C. R. Adams, R. B. Adams, R. P. Agnew, Leon Alaoglu, Warren Ambrose, R. C. Archibald, Herbert E. Arnold, H. T. R. Aude, R. P. Bailey, J. L. Barnes, R. C. F. Bartels, Felix Bernstein, R. A. Beth, E. E. Betz, Harry Birchenough, Garrett Birkhoff, G. D. Birkhoff, R. P. Boas, Salomon Bochner, C. B. Boyer, A. T. Brauer, R. W. Brink, B. H. Brown, B. L. Brown, R. E. Bruce, G. S. Bruton, J. A. Bullard, C. T. Bumer, R. S. Burington, F. J. H. Burkett, J. H. Bushey, Jewell H. Bushey, W. D. Cairns, B. H. Camp, M. E. Carlen, Leonard Carlitz, W. B. Carver, J. A. Clarkson, R. F. Clippinger, L. W. Cohen, Nancy Cole, Esther Comegys, G. M. Conwell, T. F. Cope, A. H. Copeland, L. P. Copeland, Richard Courant, A. P. Cowgill, A. T. Craig, A. R. Crathorne, H. B. Curry, D. R. Curtiss, J. H. Curtiss, Tobias Dantzig, D. R. Davis, F. F. Decker, L. S. Dederick, M. R. Demers, A. H. Diamond, C. E. Dimick, C. H. Dix, W. J. Dixon, H. A. DoBell, J. L. Doob, T. L. Downs, Arnold Dresden, John Dyer-Bennet, Samuel Eilenberg, Churchill Eisenhart, L. P. Eisenhart, M. L. Elveback, Benjamin Epstein, Paul Erdös, G. C. Evans, G. W. Evans, W. K. Feller, W. B. Fite, H. T. Fleddermann, M. M. Flood, L. R. Ford, G. E. Forsythe, Tomlinson Fort, R. M. Foster, A. H. Fox, J. S. Frame, Philip Franklin, K. O. Friedrichs, Orrin Frink, T. C. Fry, R. E. Fullerton, M. G. Gaba, H. L. Garabedian, H. J. Gay, H. P. Geiringer, B. P. Gill, R. E. Gilman, Michael Goldberg, Michael Golomb, C. H. Graves, L. J. Green, E. H. Hadlock, D. W. Hall, Marshall Hall, P. R. Halmos, Israel Halperin, J. A. Hamilton, D. C. Harkin, O. G. Harrold, O. C. Hazlett, E. R. Hedrick, M. H. Heins, Robert Henderson, J. G. Herriot, E. H. C. Hildebrandt, T. H. Hildebrandt, Einar Hille, M. P. Hollcroft, T. R. Hollcroft, G. M. Hopper, Harold Hotelling, S. E. Hotelling, E. M. Hull, E. V. Huntington, W. A. Hurwitz, M. H. Ingraham, Dunham Jackson, S. B. Jackson, Fritz John, R. A. Johnson, F. E. Johnston, A. W. Jones, B. W. Jones, H. A. Jordan, Mark Kac, M. L. Kales, E. R. van Kampen, Wilfred Kaplan, E. S. Kennedy, L. S. Kennison, S. C. Kleene, J. R. Kline, J. C. Knipp, E. R. Kolchin, W. D. Lambert, O. E. Lancaster, A. E. Landry, R. E. Langer, R. A. Leibler, B. A. Lengyel, C. A. Lester, Norman Levinson, D. C. Lewis, M. I. Logsdon, W. R. Longley, L. H. Loomis, C. I. Lubin, N. H. McCoy, E. J. McShane, L. A. MacColl, C. C. MacDuffee, Saunders MacLane, H. M. MacNeille, W. G. Madow, Dorothy Manning, L. C. Mathewson, Walther Mayer, W. E. Milne, Richard von Mises, E. B. Mode, Deane Montgomery, T. W. Moore, F. M. Morgan, W. K. Morrill, Max Morris, Marston Morse, E. J. Moulton, G. W. Mullins, C. W. Munshower, O. E. Neugebauer, John von Neumann, C. V. Newsom, A. V. Newton, Jerzy Neyman, C. O. Oakley, R. E. O'Connor, P. S. Olmstead, J. M. H. Olmsted, Isaac Opatowski, Oystein Ore, F. W. Owens, H. B. Owens, Gordon Pall, E. W. Paxson, F. W. Perkins, O. J. Peterson, C. G. Phipps, Everett Pitcher, Hillel 
Poritsky, G. B. Price, E. J. Purcell, H. A. Rademacher, E. D. Rainville, J. F. Randolph, M. S. Rees, R. W. Rempfer, Harris Rice, R. G. D. Richardson, D. E. Richmond, R. F. Rinehart, J. F. Ritt, H. E. Robbins, Robin Robinson, S. L. Robinson, Benjamin Rosenbaum, Joseph Rosenbaum, R. A. Rosenbaum, Arthur Rosenthal, J. B. Rosser, H. G. Russell, N. E. Rutt, S. T. Sanders, Peter Scherk, E. R. Schneckenburger, I. J. Schoenberg, G. E. Schweigert, C. H. W. Sedgewick, R. W. Sedgewick, W. E. Sewell, I. M. Sheffer, L. W. Sheridan, L. L. Silverman, R. G. Simond, M. E. Sinclair, Abraham Sinkov, H. L. Slobin, M. M. Slotnick, M. F. Smiley, C. E. Smith, P. A. Smith, T. L. Smith, W. M. Smith, Virgil Snyder, M. R. Solt, Joseph Spear, D. C. Spencer, V. E. Spencer, Abraham Spitzbart, G. R. Stibitz, C. N. Stokes, M. H. Stone, E. C. Strayhorn, R. E. Street, D. J. Struik, Otto Szász, Gabor Szegö, J. D. Tamarkin, J. M. Thomas, E. W. Titt, M. M. Torrey, J. I. Tracey, W. J. Trjitzinsky, A. W. Tucker, Bryant Tuckerman, J. W. Tukey, S. M. Ulam, G. B. Van Schaack, J. H. Van Vleck, H. E. Vaughan, Oswald Veblen, Abraham Wald, G. L. Walker, G. W. Walker, R. J. Walker, H. S. Wall, Charles Walmsley, J. L. Walsh, Warren Weaver, W. D. A. Westfall, A. P. Wheeler, H. S. White, A. L. Whiteman, P. M. Whitman, Hassler Whitney, J. K. Whittemore, G. T. Whyburn, W. M. Whyburn, D. V. Widder, Norbert Wiener, L. R. Wilcox, C. E. Wilder, S. S. Wilks, W. L. G. Williams, E. W. Wilson, Aurel Wintner, Audrey Wishard, E. E. Witmer, Jacob Wolfowitz, W. D. Wray.

The Colloquium Lectures on the subject Analytic topology were delivered by Professor G. T. Whyburn of the University of Virginia on Tuesday morning and afternoon and Wednesday and Thursday mornings. The presiding officers at the four lectures were, in order, President G. C. Evans, Professor J. R. Kline, Vice President C. R. Adams, and Vice President T. C. Fry.

On Thursday afternoon, by invitation of the Program Committee, Professor Leonard Carlitz of Duke University gave an address entitled Arithmetic of polynomials in a Galois field.

President G. C. Evans presided at the business meeting and Professor J. L. Walsh at the general session on Thursday morning; Professor Gordon Pall at the general session on Thursday afternoon. The presiding officers of the sectional sessions were as follows: Analysis, Professors L. W. Cohen, J. F. Randolph, I. M. Sheffer, Gabor Szegö; Algebra, Topology and Foundations, Dr. Marshall Hall; Algebra and Theory of Numbers, Professor B. W. Jones; Geometry, Professor M. G. Gaba; Mathematical Statistics (a joint session with the Institute of Mathematical Statistics), Professor B. H. Camp.

Headquarters for the meeting were in Thayer Hall. The dormitories of the college were available to the members of the three organizations and their guests.

Those attending the meetings were entertained Monday evening by a music recital, by moving pictures showing winter sports at Dartmouth, and by an exhibition of string models. On Monday after- 
noon, tea was served at the Graduate Club by the ladies of the Dartmouth faculty.

A dinner for the members of the Society, the Association and the Institute was held Tuesday evening in Thayer Hall. Professor B. H. Brown was toastmaster. The speakers were Dean E. G. Bill, Dean R. G. D. Richardson, Professors P. A. Smith, Hassler Whitney, and S. S. Wilks. The attendance was 324 .

Wednesday afternoon was devoted to an excursion to Franconia Notch.

The Bell Telephone Laboratories exhibited a machine for computing with complex numbers. The recording instrument at Hanover was connected by telegraph with the computing mechanism in New York. This machine was available to members from 11 A.M. to 2 P.M. each day of the meetings.

A resolution by Professor E. J. Purcell thanking the President, officers and members of the Mathematics Department of Dartmouth College for their competent arrangements and cordial hospitality, was adopted unanimously at the general session Thursday morning.

The Board of Trustees met on Monday at 6:00 P.M. in Thayer Hall. It reviewed the financial affairs of the Society with a view to a report to the Council.

There were three meetings of the Council, one being a joint session with the Board of Governors of the Mathematical Association of America. This joint session to hear the report of the War Preparedness Committee was held in Dartmouth Hall at 9:00 P.M. on Monday. The other meetings of the Council were in Thayer Hall at 4:30 P.M. on Tuesday and at 9:00 P.M. on Wednesday.

The Secretary announced the election of the following sixteen persons to membership in the Society:

Miss Helen C. Brodie, New York, N. Y.;

Professor D. van Dantzig, Technische Hoogeschool, Delft, Netherlands;

Professor Joseph J. Dennis, Clark University, Atlanta, Ga.;

Mr. Albert B. Farnell, University of Oklahoma;

Professor James Norman Goodier, Cornell University;

Dr. L. Louise Johnson, Reed College, Portland, Ore.;

Professor Eugene Leimanis, University of Latvia, Riga, Latvia;

Dr. Beppo Levi, The Mathematical Institute, Rosario, Argentina;

Dr. Harry Miller Lydenberg, New York, N. Y.;

Mr. (Albert) Wayne McGaughey, University of Cincinnati;

Sister Teresa M. Madden, College of Our Lady of the Elms, Chicopee, Mass.;

Mr. James R. Newman, New York, N. Y.;

Dr. Maxwell Reade, Ohio State University;

Dr. Charles V. Robinson, University of Missouri; 
Professor Arthur Rosenthal, University of Michigan;

Dr. Walter Stephen Snyder, Ohio State University.

The following appointments by President Evans were reported: as representative of the Society at the dedication of buildings at the University of Colorado on June 8-9, Professor A. J. Kempner; as chairman of the Committee on Publicity (to replace Professor C. N. Moore, who resigned), Mr. R. M. Foster; as an additional member of this Committee, Professor J. B. Rosser (the newly constituted committee is as follows: Messrs. R. M. Foster (chairman), Saunders MacLane, G. B. Price, J. B. Rosser, and J. M. Thompson); as representative of the Society at the Conference on Science, Philosophy, and Religion and Their Relation to the Democratic Way of Life, held at the Jewish Theological Seminary of America in New York City on September 9-11, 1940, Professor Hermann Weyl; as representative of the Society at the inauguration of George N. Shuster as fifth president of Hunter College on October 8-11, Professor H. S. White.

Meetings of the Society during 1941 were set as follows: in New York City on February 22; in Stanford University, California on April 5; in Washington, D. C. on May 2-3; at the University of Chicago on September 2-6; in New York City on October 25. Summer Meetings were arranged for Cornell University in 1942 and for the University of Colorado in 1943.

An invitation to meet at the University of New Hampshire on June 23-27, 1941, in connection with the Congress of Sciences and Humanities and the American Association for the Advancement of Science was received.

The Committee on War Preparedness presented an extended report, which is summarized in an article by the Chairman, Professor Marston Morse, in the September number of this Bulletin. A Roster of Scientific Personnel is being compiled by the National Resources Planning Board of the U. S. Government, and Dean L. P. Eisenhart, Professor G. C. Evans, and Dean R. G. D. Richardson represent mathematics on the committee.

The Committee on Scientific Aids to Learning (supported by funds from the Carnegie Corporation) has appropriated a sum not to exceed $\$ 10,000$ for microfilm reading machines, the distribution of which is to be for the benefit of Mathematical Reviews and to be arranged by the Executive Committee of that journal.

Reports were sent in July to the Carnegie Corporation and Rockefeller Foundation regarding their grants to Mathematical Reviews.

Certain invitations to give hour addresses were announced: Pro- 
fessors J. B. Rosser and H. S. Wall for the November 1940 meeting in Detroit, Professors Saunders MacLane and Leo Zippin for the 1940 Annual Meeting, and Professor M. R. Hestenes for the 1941 April meeting in Chicago.

The sixteenth Josiah Willard Gibbs Lecture is to be given by Professor Sewall Wright at the Summer Meeting of 1941 in Chicago. The committee to select Gibbs lecturers for 1942 and 1943 consists of Professors H. P. Robertson (chairman), N. H. McCoy, and J. L. Synge.

Professors H. E. Buchanan and H. J. Ettlinger were appointed representatives on the Council of the American Association for the Advancement of Science for 1941 and Professor F. D. Murnaghan was appointed representative on the National Research Council for a period of three years beginning July, 1941.

The report of the Committee to Consider Possible Freer Methods of Nominating and Electing Council Members as adopted by the Council provides for a decrease in the number of ex-officio members of the Council, the opportunity for choice on the ballot in the election of vice presidents and elected members of the Council, and the chance on the ballot to suggest names for the various offices for the year following. A committee consisting of Professors W. M. Whyburn (chairman), Alonzo Church, and Philip Franklin was appointed to make appropriate revisions of the By-Laws with a view to presenting them for adoption by the Society. Provision is to be made on the Council for a representative of Mathematical Reviews.

A Committee on the Award of the Cole Prize in the Theory of Numbers for the period 1936-1940 was appointed, consisting of Professors H. H. Mitchell (chairman), A. J. Kempner, and Hermanin Weyl.

A committee consisting of Professor Richard Courant (chairman), Mr. R. M. Foster, and Professor Harold Hotelling was named to consider the problem of holding informal discussion groups in regard to important papers read before the Society which touch on applications.

Titles and cross references to the abstracts of the papers read are given below. The papers were read as follows: papers 1-8 in the section for Analysis on Tuesday morning; papers 9-13 in the section for Geometry on Tuesday morning; papers 14-19 in the section for Mathematical Statistics on Tuesday afternoon; papers 20-23 in the section for Analysis on Tuesday afternoon; papers 24-31 in the section for Analysis on Wednesday morning; papers 32-38 in the section for Algebra, Topology and Foundations on Wednesday morning; papers 39-43 in the General Session on Thursday morning ; papers 44- 
50 in the section for Analysis on Thursday afternoon; papers 51-55 in the section for Algebra and Theory of Numbers on Thursday afternoon; and papers 56-96, whose abstract numbers are followed by the letter $t$, were read by title. Dr. Wundheiler was introduced by Professor D. J. Struik, Dr. Brown by Professor S. S. Wilks, Professor Zygmund by Professor T. R. Hollcroft, Dr. Hutchinson by Professor D. J. Struik, Professor Alexandroff by Professor P. A. Smith, Dr. Bergman by Dr. D. C. Spencer, Professor Hua by Professor T. R. Hollcroft, Dr. Manel by Professor Richard Courant, Professor Pólya by Professor Einar Hille, and Mr. Rosenthall by Professor E. T. Bell. Paper 1 was presented by Dr. Stephan Bergman, paper 4 by Mr. Epstein, paper 8 by Dr. Poritsky, paper 12 by Professor Struik, paper 21 by Dr. Boas, paper 22 by Dr. Halmos, paper 30 by Dr. Spencer, paper 31 by Professor Wiener, paper 38 by Dr. Hall, paper 39 by Professor Bochner, and paper 46 by Dr. Alaoglu.

1. Abe Gelbart: On approximations of functions of two complex variables regular in multiply-connected four-dimensional domains. (Abstract 46-9-418.)

2. K. O. Friedrichs: On hyperbolic differential operators. (Abstract 46-9-416.)

3. Orrin Frink: Series expansions in linear vector space. (Abstract 46-9-417.)

4. D. G. Bourgin and Benjamin Epstein: $A$ class of kernels generated by a Laplace-Mellin transformation. (Abstract 46-11-448.)

5. Isaac Opatowski: On the motion of an electric particle. (Abstract 46-11-468.)

6. D. C. Harkin: Fourier series as limits of Gaussian sums. (Abstract 46-11-457.)

7. Einar Hille: $A$ class of differential operators of infinite order. (Abstract 46-11-491.)

8. Hillel Poritsky and H. D. Snively: Doubly periodic networks. (Abstract 46-11-471.)

9. Alexander Wundheiler: Some basic notions in meta-geometry. (Abstract 46-9-445.)

10. Marshall Hall: Projective planes. (Abstract 46-9-421.)

11. W. L. G. Williams: The application of hyperbolic complex numbers to the geometry of the triangle. (Abstract 46-11-482.)

12. D. J. Struik and Alexander Wundheiler: Affine representation of systems of forces. (Abstract 46-9-439.)

13. E. J. Purcell: Space Cremona transformations of order $m+n-1$. (Abstract 46-9-433.)

14. Hilda P. Geiringer: A generalization of the law of large numbers. (Abstract 46-11-455.) 
15. S. S. Wilks: On the problem of two samples from normal populations with unequal variances. (Abstract 46-11-481.)

16. Harold Hotelling: Experimental determination of the maximum of an empirical function. (Abstract 46-9-424.)

17. Abraham Wald: Asymptotically shortest confidence intervals. (Abstract 46-11-479.)

18. G. W. Brown: Reduction of certain composite statistical hypotheses. (Abstract 46-11-449.)

19. Jerzy Neyman: Conception of equivalence in the limit of statistical tests and its application to certain forms of $\chi^{2}$ and to the tests based on the $\lambda$ principle. (Abstract 46-11-467.)

20. J. F. Randolph: Some properties of sets of the Cantor type. (Abstract 46-11-472.)

21. R. P. Boas and D. V. Widder: Functions with positive differences. (Abstract 46-9-404.)

22. P. R. Halmos and R. A. Leibler: Square roots of measure preserving transformations. (Abstract 46-9-422.)

23. Antoni Zygmund: Power series of the class $H^{\lambda}$ on the circle of convergence. (Abstract 46-11-483.)

24. J. G. Herriot: Nörlund summability of double Fourier series. Preliminary report. (Abstract 46-9-423.)

25. M. H. Heins: $A$ proof of Picard's theorem by the fundamental theorem on the conformal mapping of simply-connected Riemann surfaces. Abstract 46-11-459.)

26. I. M. Sheffer: On the singularities of functions under certain linear transformations. (Abstract 46-11-475.)

27. I. J. Schoenberg: On positive definite functions on spheres. (Abstract 46-11-474.)

28. W. J. Trjitzinsky: Properties of growth for solutions of differential equations of dynamical type. (Abstract 46-11-478.)

29. J. M. H. Olmsted: Lebesgue theory on a Boolean algebra. Preliminary report. (Abstract 46-9-430.)

30. Stefan Bergman and D. C. Spencer: On distortion in pseudoconformal mapping. (Abstract 46-9-402.)

31. Norbert Wiener and Aurel Wintner: Discrete chaos. (Abstract 46-11-480.)

32. P. M. Whitman: Splittings of a lattice. (Abstract 46-9-442.)

33. L. R. Wilcox: $A$ topology for semi-modular lattices. (Abstract 46-9-443.)

34. O. G. Harrold (National Research Fellow): Characterizations of some continua by continuous functions. Preliminary report. (Abstract 46-11-458.) 
35. Everett Pitcher: The cap heights of a sum function on a product space. (Abstract 46-11-470.)

36. S. C. Kleene: Recursive predicates and quantifiers. Preliminary report. (Abstract 46-11-464.)

37. Samuel Eilenberg: On homotopy groups. (Abstract 46-11-453.)

38. D. W. Hall and W. T. Puckett: Strongly arcwise connected sets. (Abstract 46-11-456.)

39. Salomon Bochner and I. J. Schoenberg: On positive definite functions on compact spaces. (Abstract 46-11-447.)

40. Gordon Pall: On the arithmetic of ternary quadratic forms. (Abstract 46-11-469.)

41. R. E. Langer: On the theory of irregular differential boundary problems. Preliminary report. (Abstract 46-11-465.)

42. G. C. Evans: Surfaces of minimum capacity. (Abstract 46-9413.)

43. H. B. Curry: The inconsistency of certain formal logics. (Abstract 46-11-451.)

44. Warren Ambrose: Change of velocities in a continuous ergodic flow. Preliminary report. (Abstract 46-11-446.)

45. Benjamin Epstein: A contribution to the theory of two complex variables in certain domains. (Abstract 46-9-412.)

46. Leon Alaoglu, Garrett Birkhoff, and B. J. Pettis: General ergodic theorems. II. Preliminary report. (Abstract 46-9-394.)

47. Fritz John: Discontinuous convex solutions of difference equations. (Abstract 46-9-425.)

48. J. H. Curtiss: Necessary conditions in the theory of interpolation in the complex domain. (Abstract 46-7-378.)

49. Otto Szász: On the jump of almost periodic functions and Fourier integrals. (Abstract 46-9-399.)

50. H. T. Fleddermann: The equality of measure functions. (Abstract 46-9-414.)

51. L. C. Hutchinson: On the classification of the trivector. (Abstract 46-11-460.)

52. Mark Kac: On a question of Ramanujan. (Abstract 46-9-426.)

53. J. S. Frame: The double cosets of a finite group. (Abstract 46-9415.)

54. A. T. Brauer: On a property of $k$ consecutive integers. (Abstract 46-9-405.)

55. John Dyer-Bennet: A note on partitions of the set of positive integers. (Abstract 46-9-411.)

56. Paul Alexandroff: General combinatorial topology. (Abstract 46-7-374-t.) 
57. Stefan Bergman: Boundary values of functions satisfying partial differential equations of elliptic type. (Abstract 46-9-401-t.)

58. R. P. Boas: A general moment problem. (Abstract 46-9-403-t.)

59. Herbert Busemann and Walther Mayer: On the foundations of calculus of variations. (Absract 46-9-406-t.)

60. Leonard Carlitz: On the Staudt-Clausen theorem. (Abstract 4611-450-t.)

61. R. H. Cole: The expansion problem associated with an ordinary linear differential equation and boundary conditions applying at a set of collinear points. (Abstract 46-9-407-t.)

62. H. V. Craig: On extensors. (Abstract 46-9-408-t.)

63. H. B. Curry: $A$ revision of the fundamental rules of combinatory logic. (Abstract 46-9-409-t.)

64. H. B. Curry: Consistency and completeness of the theory of combinators. (Abstract 46-9-410-t.)

65. M. M. Day: Ordered sets and closures. (Abstract 46-9-395-t.)

66. Samuel Eilenberg: Local connectedness in higher dimensions. (Abstract 46-11-452-t.)

67. C. H. Forsyth: Statistical interpretations of the first auxiliaries of the Gaussian symmetrical method. (Abstract 46-11-454-t.)

68. H. L. Garabedian, H. S. Wall, and Einar Hille: Hausdorff means and integral equations. (Abstract 46-9-397-t.)

69. L. J. Green: Twisted cubics associated with a space curve. II. (Abstract 46-9-419-t.)

70. D. W. Hall and W. T. Puckett: Arc-preserving transformations of a certain class of spaces. (Abstract 46-9-420-t.)

71. O. G. Harrold (National Research Fellow): A note on strongly irreducible maps of an interval. (Abstract 46-7-381-t.)

72. Loo-Keng Hua: Some "Anzahl" theorems in the theory of groups of prime-power order. (Abstract 46-11-492-t.)

73. Loo-Keng Hua: The lattice points in a circle. (Abstract 46-11493-t.)

74. W. H. Ingram: A generalization of Erhard Schmidt's solution of the nonhomogeneous integral equation. Preliminary report. (Abstract 46-11-494-t.)

75. Nathan Jacobson: Restricted Lie algebras of characteristic p. (Abstract 46-11-461-t.)

76. R. L. Jeffery: Integration in abstract space. (Abstract 46-11-462t.)

77. F. B. Jones: Quasi-continuous curves and certain boundary problems. (Abstract 46-11-463-t.)

78. Edward Kasner and J. J. DeCicco: Equilong and conformal transformations of period two. (Abstract 46-9-398-t.) 
79. W. H. McEwen: On the degree of convergence of a series associated with an integro-differential system. (Abstract 46-9-427-t.)

80. W. G. Madow: Contributions to the theory of the representative method of sampling. (Abstract 46-11-466-t.)

81. Bella Manel: Conformal mapping of multiply connected domains on the basis of Plateau's problem. (Abstract 46-7-384-t.)

82. H. E. Newell: On the asymptotic forms of the solutions of an ordinary linear matric differential equation in the complex domain. Preliminary report. (Abstract 46-9-428-t.)

83. Rufus Oldenburger: La teoria de los polinomios de orden superior. (Abstract 46-9-429-t.)

84. F. W. Perkins: Polygonal and polyhedral means of functions. Preliminary report. (Abstract 46-9-431-t.)

85. G. Pólya: Sur l'existence de fonctions entières satisfaisant d certaines conditions linéaires. (Abstract 46-9-432-t.)

86. W. T. Reid: A new class of self-adjoint boundary value problems. (Abstact 46-11-473-t.)

87. J. F. Ritt: On a type of algebraic differential manifold. (Abstract 46-9-434-t.)

88. L. B. Robinson: Singular solutions of nonlinear functional equations. (Abstract 46-9-435-t.)

89. R. M. Robinson: Stencils for solving $x^{2} \equiv a(\bmod m)$. (Abstract 46-9-436-t.)

90. E. Rosenthall: On the diophantine equation $x^{3}+y^{3}=z^{3}+w^{3}$. (Abstract 46-9-437-t.)

91. A. R. Schweitzer: Concerning general abstract relational spaces. II. (Abstract 46-9-438-t.)

92. D. C. Spencer: On an inequality of Grunsky. (Abstract 46-11476-t.)

93. Gabor Szegö: Power series with multiply monotonic sequences of coefficients. (Abstract 46-11-477-t.)

94. J. L. Walsh and W. E. Sewell: Degree of polynomial approximation to analytic functions. Problem $\beta$. (Abstract 45-7-369-t.)

95. J. H. C. Whitehead: On incidence matrices,' nuclei and homotopy types. (Abstract 46-9-441-t.)

96. Orla V. Wood: On relations between solutions of the differential equation of the second order with four regular singular points. (Abstract 46-9-444-t.)

T. R. Hollcroft, Associate Secretary 